NATIONAL LABORATORY

MANAGED BY UT-BATTELLE

FOR THE DEPARTMENT OF ENERGY

\title{
A Deployable Fast-Neutron Coded- Aperture Imager for Quantifying Nuclear Material
}

\section{July 2013}

Prepared by

Paul Hausladen

Jason Newby

Felix Liang

Matthew Blackston

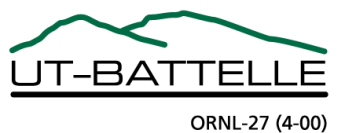




\title{
DOCUMENT AVAILABILITY
}

Reports produced after January 1, 1996, are generally available free via the U.S. Department of Energy (DOE) Information Bridge.

Web site http://www.osti.gov/bridge

Reports produced before January 1, 1996, may be purchased by members of the public from the following source.

\author{
National Technical Information Service \\ 5285 Port Royal Road \\ Springfield, VA 22161 \\ Telephone 703-605-6000 (1-800-553-6847) \\ TDD 703-487-4639 \\ Fax 703-605-6900 \\ E-mail info@ntis.gov \\ Web site http://www.ntis.gov/support/ordernowabout.htm
}

Reports are available to DOE employees, DOE contractors, Energy Technology Data Exchange (ETDE) representatives, and International Nuclear Information System (INIS) representatives from the following source.

Office of Scientific and Technical Information

P.O. Box 62

Oak Ridge, TN 37831

Telephone 865-576-8401

Fax 865-576-5728

E-mail reports@osti.gov

Web site http://www.osti.gov/contact.html

This report was prepared as an account of work sponsored by an agency of the United States Government. Neither the United States Government nor any agency thereof, nor any of their employees, makes any warranty, express or implied, or assumes any legal liability or responsibility for the accuracy, completeness, or usefulness of any information, apparatus, product, or process disclosed, or represents that its use would not infringe privately owned rights. Reference herein to any specific commercial product, process, or service by trade name, trademark, manufacturer, or otherwise, does not necessarily constitute or imply its endorsement, recommendation, or favoring by the United States Government or any agency thereof. The views and opinions of authors expressed herein do not necessarily state or reflect those of the United States Government or any agency thereof. 


\title{
A DEPLOYABLE FAST-NEUTRON CODED-APERTURE IMAGER FOR QUANTIFYING NUCLEAR MATERIAL
}

\author{
Paul Hausladen \\ Jason Newby \\ Felix Liang \\ Matthew Blackston
}

Date Published: July 2013

\author{
Prepared by \\ OAK RIDGE NATIONAL LABORATORY \\ Oak Ridge, Tennessee 37831-6283 \\ managed by \\ UT-BATTELLE, LLC \\ for the \\ U.S. DEPARTMENT OF ENERGY \\ under contract DE-AC05-00OR22725
}





\section{CONTENTS}

Page

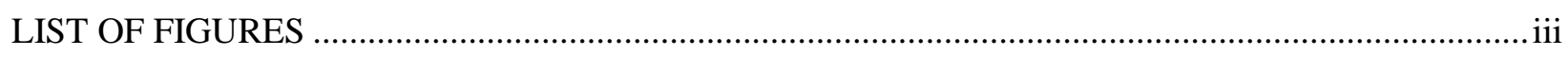

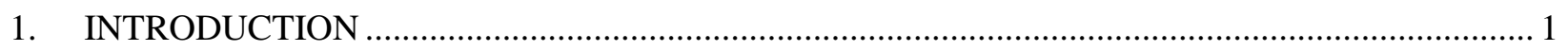

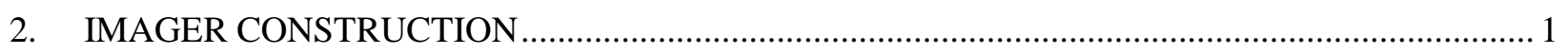

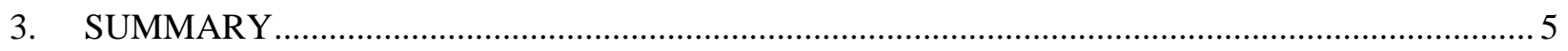

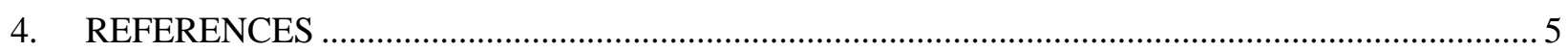

\section{LIST OF FIGURES}

Figure

1 The fast-neutron imager: (a) a schematic diagram identifying the aperture, detector, and linear stage components, (b) a photograph of the imager from the same view, and (c) a photograph of the imager from the front, showing the aperture mask. ......................................... 2

2 The components and assembly of a single detector module. From left to right, the pixel array, light guide, assembled detector, and assembled detector in its housing are shown.

3 The back of the imager (left) with covers in place and (right) with covers removed to show the detector array, surrounding HDPE shielding. 



\section{INTRODUCTION}

This brief report describes a newly constructed fast-neutron coded-aperture imager intended for performing quantitative measurements of plutonium holdup at fuel cycle facilities. The present report was prepared in fulfillment of milestone M4FT-13OR0402053, "Construct Imager," of Fuel Cycle R\&D Material Protection, Accounting, and Control Technology (MPACT) work package FT-13OR040205, "Fast-Neutron Imaging to Quantify Nuclear Materials - ORNL." The first measurements taken with the imager will be reported later this year.

For quantifying plutonium holdup, fast-neutron imaging is an appealing mode of measurement in scenarios where contact measurements with non-imaging detectors may be impractical or their results ambiguous because of surrounding material or nearby sources. The use of fast neutrons (as opposed to the more numerous gamma rays) is appealing because of their ability to penetrate equipment and nuclear material that is opaque to gamma radiation. However, the ability of fast neutrons to penetrate material also leads to challenges in constructing a fast-neutron imager sufficiently compact to be amenable for use in a facility while remaining sufficiently sensitive to neutron emanations from plutonium or other actinides. Furthermore, while fast-neutron detection is commonly achieved via organic liquid scintillators, use of the imager in a production environment favors mechanically robust detectors that do not contain flammable liquid. In response to these challenges, Oak Ridge National Laboratory (ORNL) has built a fast-neutron imager that has a compact footprint and whose segmented neutron detectors are built from the first cast plate of the recently developed plastic scintillator with pulse shape discrimination properties developed by Lawrence Livermore National Laboratory and commercially available from Eljen Technologies as experimental scintillator EJ-299-34 [1].

\section{IMAGER CONSTRUCTION}

In this section, a brief description of the imager is given as well as some of the rationale for the design choices. The present imager design reuses much of the design of a previous fast-neutron imager built at ORNL [2,3]. While successful as a laboratory device, the previous imager was large and unwieldy, and the neutron detectors (whose active volume consisted of commercially available liquid scintillator EJ-309) were fragile to mechanical shock and temperature changes that were relatively modest.

In order to be deployable, the present imager needed to be more compact and robust to withstand shipment to and from and use in a fuel cycle facility. Like the previous imager, the new imager consists of an aperture mask and a position-sensitive fast-neutron imaging detector whose relative positions are set with a linear stage in order to adjust the field of view. A schematic diagram of the major imager components is shown in Fig. 1 (a), and the corresponding photograph of the imager is shown in Fig. 1 (b). The linear stage adjusts the mask-detector separation between a minimum of $23 \mathrm{~cm}$ and a maximum separation of $44 \mathrm{~cm}$ (measured from the center of the detector active volume to the center of the mask). The total length of the imager 
is $121 \mathrm{~cm}$ (when the mask-detector separation is less than $28 \mathrm{~cm}$ ). At larger mask-detector separations, the electronics module protrudes from the back of the imager and increases the length of the imager to a maximum of $137 \mathrm{~cm}$ at maximum mask-detector separation. Note that with the present neutron detector module length of $50 \mathrm{~cm}$, a mask-detector separation of $40 \mathrm{~cm}$, and a mask thickness of $10 \mathrm{~cm}$, it would be difficult to make the scale of the imager smaller than $1 \mathrm{~m}$. The mask assembly can be rotated about its vertical axis in order to fit through a standard (36 in.) doorway.
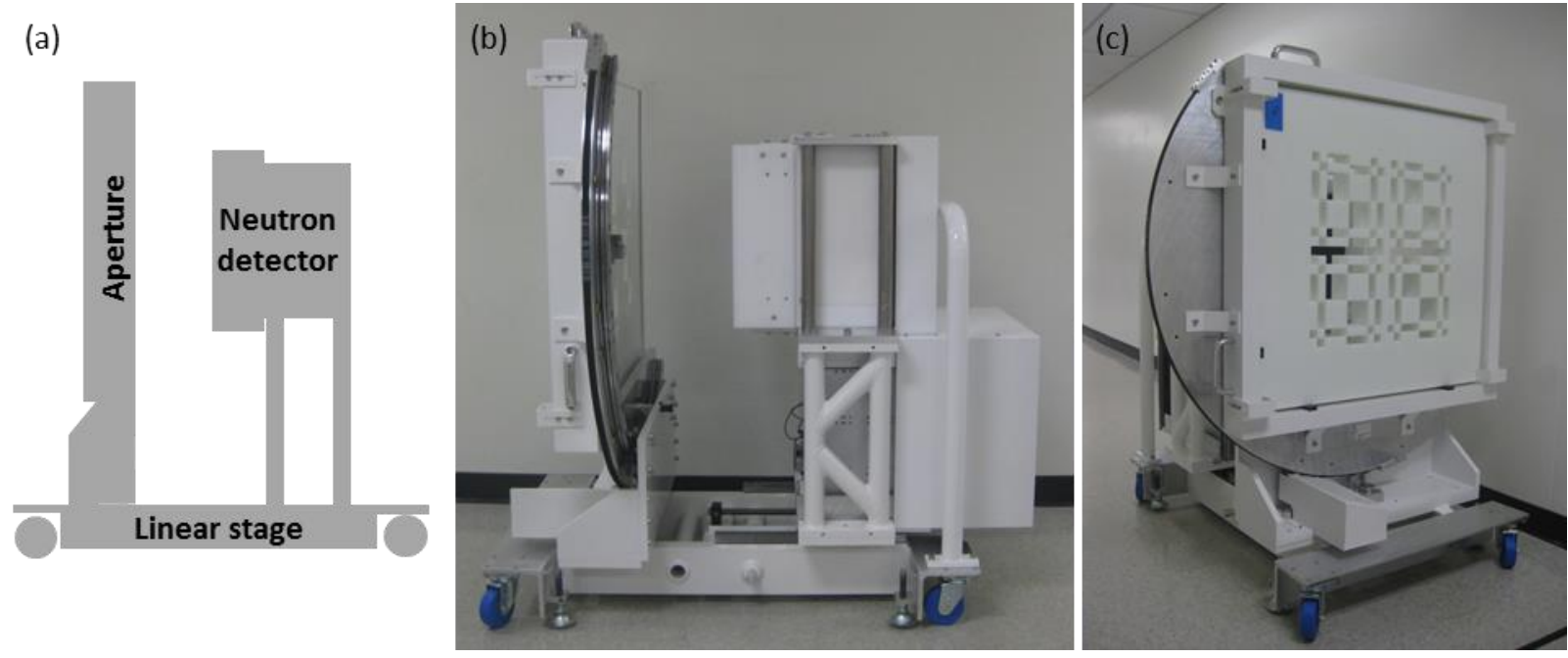

Fig. 1. The fast-neutron imager: (a) a schematic diagram identifying the aperture, detector, and linear stage components, (b) a photograph of the imager from the same view, and (c) a photograph of the imager from the front, showing the aperture mask.

A photograph of the imager from the front better showing the aperture pattern is shown in Fig. 1 (c). The aperture mask chosen for the imager is a rank-11 modified uniformly redundant array (MURA) coded aperture constructed of high-density polyethylene (HDPE) [4]. The mask pattern was machined in each of three $81 \mathrm{~cm} \times 81 \mathrm{~cm} \times 2.54 \mathrm{~cm}$ pieces of HDPE that can be stacked to yield a thickness up to $7.62 \mathrm{~cm}$. The holder for the mask can accommodate mask thicknesses up to $10 \mathrm{~cm}$. In the selected aperture pattern, the size of the 11 -element base pattern is $26.7 \mathrm{~cm}$. Using a rank-11 MURA, the field of view is divided into a $11 \times 11$ grid of uniquely identifiable basis directions. Consequently, the inherent resolution of such a mask corresponds to the field of view divided by the mask rank. The size of the pattern was chosen to give a field of view of $2 \mathrm{~m}$ at source-to-mask distances between 1.5 and $3 \mathrm{~m}$, depending on the separation of the mask and detector.

For the MURA pattern, the positions of the closed and open portions of the mask can be interchanged by rotating the mask by 90 degrees. By measuring in both of these configurations (referred to as "mask" and "antimask" configurations, respectively), background counts that have not been modulated by the mask but may not be uniform across the detector can be eliminated. In the present imager, rotation between mask and antimask configurations has been automated. However, note that in order to save size and weight, the aluminum mask rotation mechanism 
visible in Fig. 1 (c) is not symmetric when rotated 90 degrees. As a result, background counts from sources just outside the field of view will still be modulated by this mechanism. This effect will prove a complication when using the imager to scan along a large piece of equipment containing sources, since the sources are very likely to be just outside the field of view at some point in the scan.

The use of a rank-11 mask is a reduction in resolution compared to the previous imager, whose mask rank was 19. The lower mask rank was chosen for a number of reasons. First, for extended sources that subtend more than one of the basis directions, that is, "that cover more than one image pixel," lower-resolution masks are more sensitive. For plutonium holdup measurements, an accurate measurement of the plutonium mass will typically be more important than highresolution determination of the configuration. The decreased sensitivity of higher-resolution masks originates from each image pixel having the statistical uncertainty of all the counts in the detector; when summing the contribution from different pixels, these uncertainties compound. Specifically, the relative time to achieve a given uncertainty in source strength increases in proportion to the number of image pixels the source subtends. Second, a lower-resolution mask enables a more compact imager size. In order that the mask have as much contrast as possible, it is advisable to use as thick a mask as possible while still allowing each detector pixel to see through each mask opening. With fewer mask openings, each individual opening is larger, allowing larger-angle neutrons to traverse the openings and consequently closer placement of the mask to the detector. In order to shrink the overall size of the imager, smaller mask-detector separations were needed, and consequently, a smaller mask rank. Third, use of a lower-resolution mask lowered the cost of the imager. In practice, the number of detector pixels should be sufficient to at least double-sample the mask pixels. The smaller number of detector pixels required to accomplish double-sampling for the lower-rank mask enabled the use of fewer detectors at lower cost. Furthermore, the smaller size of the neutron detector array allows for more robust shielding around the array; adequate shielding of the detector from both gamma-ray and neutron sources outside the field of view is essential for preserving the sensitivity of the imager to sources in the field of view. The present design allows for $5 \mathrm{~cm}$ of HDPE shielding surrounding the sides of the detector array.

The neutron detector portion of the imager consists of a panel of nine individual detectors that are packed closely together in a $3 \times 3$ array to give a total area of $33.7 \times 33.7 \mathrm{~cm}^{2}$ and comprises 576 individual pixels in a 24 pixel $\times 24$ pixel array. The $24 \times 24$ array of detector pixels is sufficient to double-sample the apertures in the mask base pattern. The detectors and their performance have been described previously [5], but a brief description is repeated here for clarity. The active volume of a single detector module, typically referred to as the "pixel block," consists of a $108 \times 108 \times 5 \mathrm{~mm}^{3}$ volume of scintillator EJ-299-34 segmented by thin films of $3 \mathrm{M}$ Vikuiti reflector into an $8 \times 8$ array of $13.5 \times 13.5 \times 50 \mathrm{~mm}^{3}$ optically isolated pixels of plastic scintillator. The pixels are viewed through a $28-\mathrm{mm}$-thick segmented acrylic light guide by four 52 mm Hamamatsu R7724-100 super bialkali photomultiplier tubes (PMTs) whose shared 
response determines the pixel of interaction. The detector module is placed in a housing whose external dimensions in the imaging plane are $112 \mathrm{~mm} \times 112 \mathrm{~mm}$. The active area therefore comprises $92 \%$ of the total. Photographs of the constituent scintillator pixel array, light guide, assembled active components, and assembled detector in its housing are shown in Fig. 2.

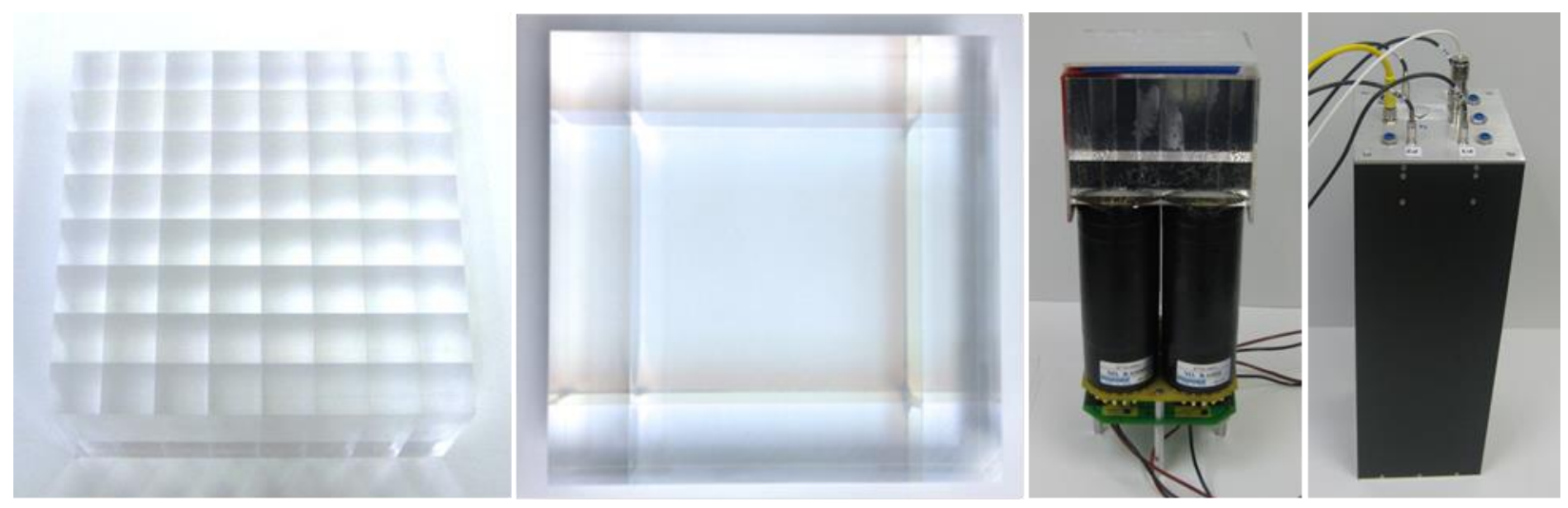

Fig. 2. The components and assembly of a single detector module. From left to right, the pixel array, light guide, assembled detector, and assembled detector in its housing are shown.

Power supplies for the detectors and data acquisition components are mounted in a PXI electronics chassis that is mounted below the detector array. The neutron detectors in the array are supplied high voltage from a common Iseg EHQ 102M high-voltage supply that is mounted in the PXI chassis. The overall gain of each detector and the gain of the individual PMTs in the detectors are matched by adjusting 20-turn HV trim pots on the back of each detector. Any additional gain matching is done by software. Readout of the four PMT signals of each detector is accomplished using four channels of a set of XIA Pixie-16 14-bit $250 \mathrm{MSs}^{-1}$ waveform digitizers mounted in the PXI chassis. The signal presented to each channel of a waveform digitizer corresponds to a PMT anode pulse integrated on a preamplifier to yield a charge pulse with a relatively short decay time $(2.5 \mu \mathrm{s})$. While the full waveform of the pulse could be used, most of the information that is present in the waveform can be summarized in a few points. This summary is recorded and used to calculate the pulse shape and the position of interaction in the detector. Custom firmware and the architecture of the XIA system allow triggering of synchronous digitization of four channels (corresponding to the four PMTs) with the sum signal to support correct position calculation. Readout of the Pixie-16 digitizers is accomplished over the PCI bus by a National Instruments NI PXI-8109 embedded controller which broadcasts the data to a remote computer via gigabit Ethernet. In Fig. 3, the rear view of the imager is shown with covers in place, and also with the covers removed to show the nine-detector array, the surrounding HDPE shielding, and the PXI chassis holding the embedded controller, digitizers, and power supplies. 

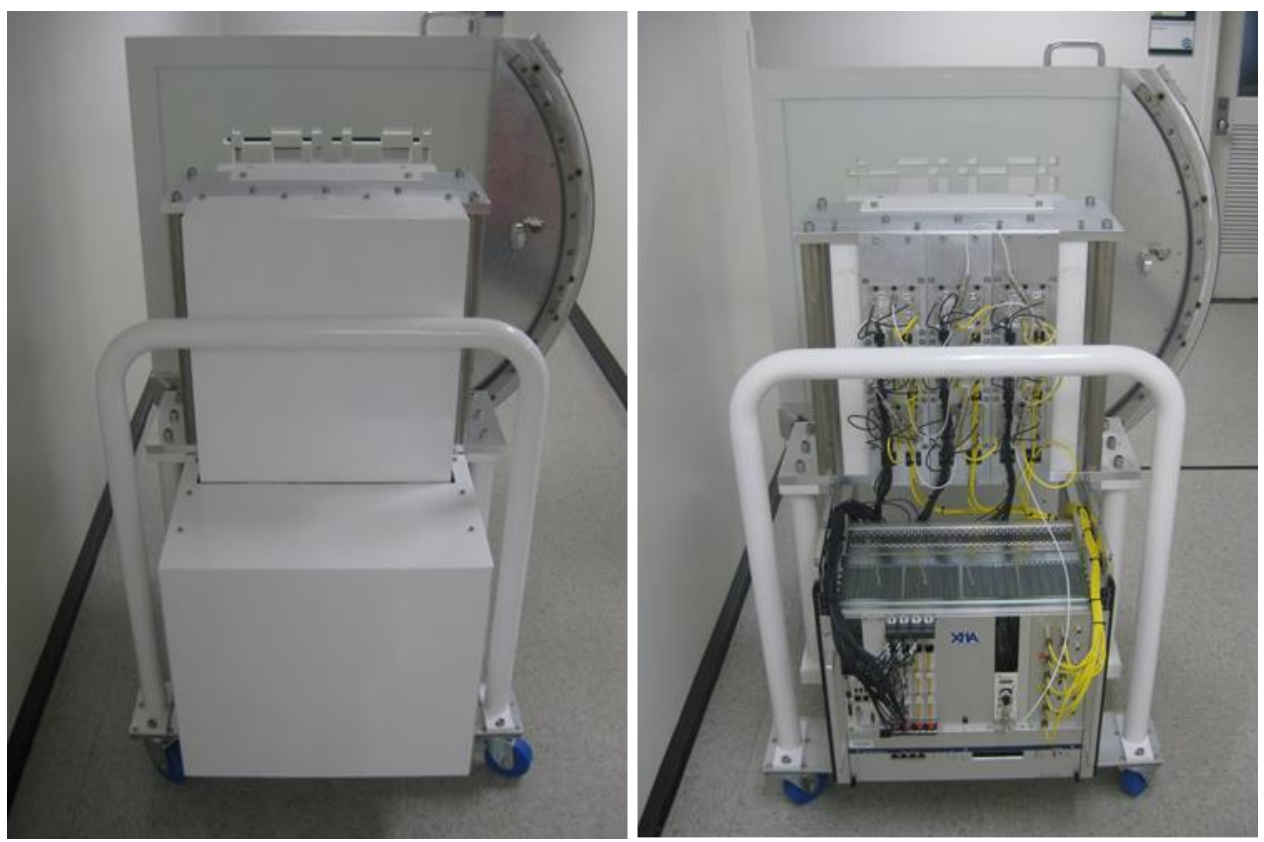

Fig. 3. The back of the imager (left) with covers in place and (right) with covers removed to show the detector array, surrounding HDPE shielding.

\section{SUMMARY}

ORNL has constructed a new, compact fast-neutron coded aperture imager intended for use in performing quantitative measurements of plutonium holdup at fuel cycle facilities. The design has been chosen to reduce cost, to achieve a more compact size for the imager, and to favor sensitivity over angular resolution. At present, ORNL is working to incorporate a Microsoft Kinect ${ }^{\circledR}$ camera and rangefinder in order to support data fusion of visual image, radiation image, and depth. ORNL is looking forward to performing commissioning measurements with the imager in the upcoming months.

\section{REFERENCES}

[1] N. Zaitseva, B. L. Rupert, I. Pawełczak, A. Glenn, H. P. Martinez, L. Carman, M. Faust, N. Cherepy, and S. Payne, "Plastic scintillators with efficient neutron/gamma pulse shape discrimination," Nuclear Instruments and Methods in Physics Research A, 668, 88 (2012).

[2] P. A. Hausladen, M. A. Blackston, E. Brubaker, D. L. Chichester, P. Marleau, and R. J. Newby, "Fast-Neutron Coded-Aperture Imaging of Special Nuclear Material Configurations," 53rd Annual Meeting of the INMM, Orlando, FL, USA, 2012.

[3] P. Hausladen, M. Blackston, F. Liang, and J. Newby, Measurements and Analysis of Mock Holdup Configurations Using Fast-Neutron Imaging, ORNL/TM-2012/400.

[4] S. R. Gottesman and E. E. Fenimore, "New family of binary arrays for coded aperture imaging," Applied Optics, 28(20), 4344-4352 (1989).

[5] R. J. Newby, P. A. Hausladen, M. A. Blackston, and J. F. Liang, Performance of FastNeutron Imaging Detectors Based on Plastic Scintillator EJ-299-34, ORNL/TM-2013/82. 